\title{
Dual-Label Detection of Amplified Products in Quantitative RT-PCR Assay Using Lanthanide- Labeled Probes
}

BioTechniques 30:832-845 (April 2001)

\author{
Alice Ylikoski, Matti Karp, \\ Hans Lilja ${ }^{1}$, and Timo \\ Lövgren \\ University of Turku, Turku, \\ Finland and ${ }^{1}$ Lund University, \\ Malmö, Sweden
}

\begin{abstract}
Quantitative RT-PCR (QRT-PCR) enables the sensitive and specific detection of $m R N A$ with a small copy number. We used the QRT-PCR method and dual-label analysis of amplification products for the detection of prostate-specific antigen (PSA) $m R N A$. The QRT-PCR assay employed a PSA-like internal standard (IS) mRNA, which was used to quantify the PSA mRNA copies and to control the variations during the whole assay procedure from the RNA extraction to the detection of QRT-PCR am plification products by hybridization assay. After co-amplification, the PSA and IS products were detected in a microplate using $\mathrm{Eu}^{3+}$ chelate-labeled PSA and $\mathrm{Tb}^{3+}$ chelate-labeled IS hybridization probes. The detection probes allowed the simultaneous and dual-label detection of PSA and IS products in the same microtiter well. Com pared to the single-label assay, the dual-label detection improved the within-and between-assay $\mathrm{CV} \%$ from 21.7 to 7.5 and from 36.0 to 30.3, respectively. The between-and within-assay variation of the dual-label assay was further studied using PSA-producing LNCaP cells. The cells were found to express $980 \pm 170$ (mean \pm SD) copies of PSA-mRNA with the within-assay $\mathrm{CV} \%$ of 17.7 and $890 \pm 220$ (mean $\pm S D)$ copies of PSA-mRNA with the between-assay CV\% of 25.0. The methodology developed may help in future studies to obtain reliable quantification of PSA mRNA generated by circulating prostate cancer cells.
\end{abstract}

\section{INTRODUCTION}

Time-resolved fluorometry (TRF) with lanthanide chelates is a very sensitive technique that utilizes the long decay time and the large shift between the excitation and emission wavelengths (Stokes shift) of the lanthanide chelates $(18,34)$. The long decay time allows the detection of the specific fluorescence after a time delay, during which the rapidly decreasing background fluorescence from the sample dies out. We have previously utilized TRF with single-label detection of the products am plified in quantitative RT-PCR (QRTPCR) for prostate-specific antigen (PSA) mRNA (44). The use of different lanthanide chelates permits the detection of multiple analytes in the same reaction because of the sharp emission peaks and the different decay times of the lanthanides (Figure 1). The TRF technology and the detection of multiple analytes have been widely used in both hybridization assays for DNA and immunoassays $(13,14,20,29,31,38,43)$. One of the most multiplexed assays has employed seven colors in TRF-based hybridization analysis (30).

RT-PCR is an important method for the determination of gene expression $(1,3,41)$. RT-PCR assays have been used for the detection of specific tumor- or tissue-associated markers to monitor metastatic tumor cells in the blood, lymph nodes, or other organs $(17,19,32)$. For the detection of prostate cancer cells in blood and lymph node samples, a widely studied target is PSA mRNA $(8,15,16,21,40)$. However, the data from different studies seem to disagree with the power of RT-PCR assays for PSA mRNA to predict the micrometastatic spread and clinical stage and to monitor the treatment efficacy
$(6,33,35)$. Some studies suggest the development of more standardized and reproducible QRT-PCR assays to further study the utility of this technique in the molecular staging of prostate cancer $(7,26)$. There are several quantitative methods utilizing different approaches to detect the target mRNA. Some of the studies have used an endogenous calibrator for the relative quantification of the target mRNA, while others have employed an exogenous control and/or an external calibration curve for the quantification (1-3, $23,27,28,38,39,41,42,44)$. The endogenous and exogenous calibrators or controls can be either internal (to be amplified in the same reaction tube with the target) or external (to be amplified in a separate tube from the target).

Our study was designed to develop a dual-analyte hybridization assay for the quantitative and nonradioactive detection of RT-PCR-amplified PSA and internal standard (IS) products and to determine whether the reproducibility of the assay could be improved by this simultaneous detection. The assay describes a TRF and lanthanide-labeled, oligonucleotide-based detection of QRT-PCR amplification products. The QRT-PCR assay for PSA mRNA contains a novel exogenous IS mRNA and an external calibration curve. The IS mRNA has only a 2-bp deletion with respect to the wild-type PSA mRNA, and purified IS and PSA mRNAs are used to generate the calibration curve for each experiment. In addition, unlike in the existing assays in which the IS RNA is added to the sample at the beginning of cDNA synthesis, in our assay, a known amount of the IS mRNA is added into each sample at the beginning of RNA extraction. This permits us to quantify the PSA mRNA copies in the denatured 
cell samples and to control variations from the beginning of the RNA extraction to the detection of the amplification products by hybridization. The PSA and IS mRNA are co-amplified in QRTPCR with the same primers, and the amplification products are detected on a streptavidin-coated microtiter well with specific hybridization probes. The PCR products are immobilized on the microtiter well. After denaturation into a single-stranded form, the $\mathrm{Tb}^{3+}$ chelatelabeled IS and the $\mathrm{Eu}^{3+}$ chelate-labeled PSA probes are allowed to hybridize simultaneously. The signals of the bound probes are measured by TRF technology, which gives numerical values and allows the calculation of the PSA mRNA copies in the sample by comparing the PSA-to-IS fluorescence ratio of the sample to the ratio in the calibration curve. The developed assay may enable more quantitative and accurate detection of PSA mRNA in prostate cancer cells shed into the blood, lymph nodes, or bone marrow.

\section{MATERIALS AND METHODS}

\section{Cell Lines}

The PSA-expressing human prostatic carcinoma cell line LNCaP and the non-PSA-producing mouse myeloma cell line SP2/0 were obtained from the ATCC (Manassas, VA, USA). The cell

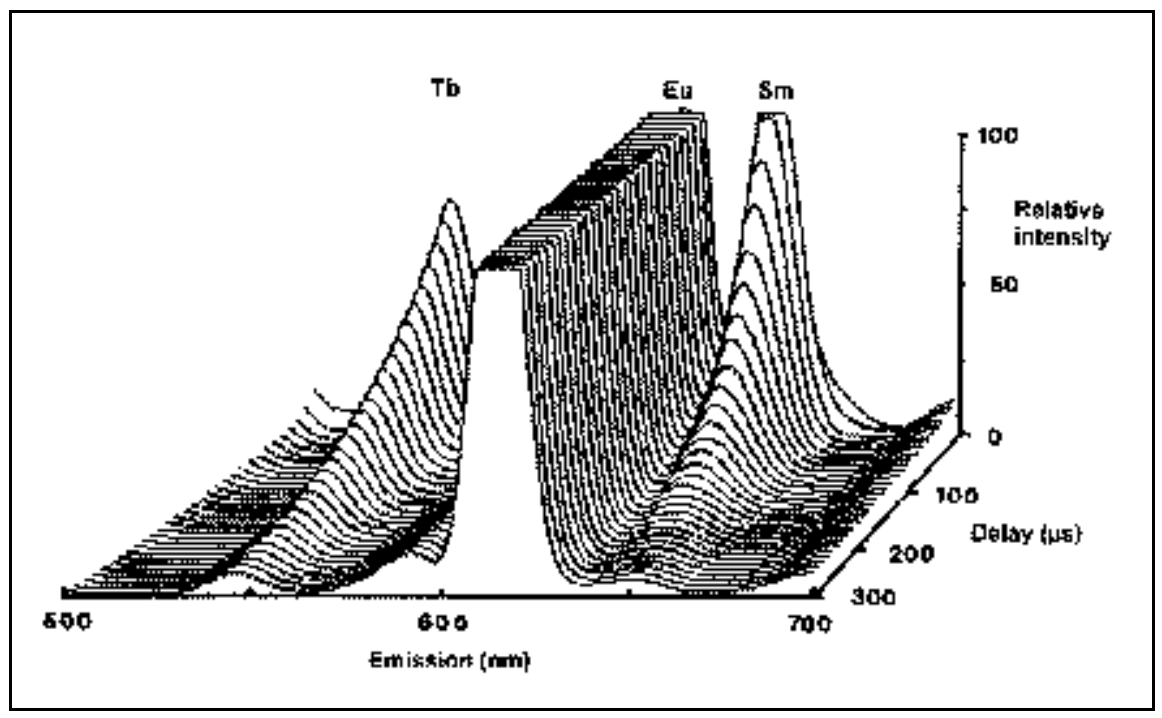

Figure 1. Principle of time-resolved fluorometry. Emission spectra and decay profiles of $\mathrm{Tb}^{3+}, \mathrm{Eu}^{3+}$ and $\mathrm{Sm}^{3+}$ chelates.

lines were cultured in flasks containing DMEM (Life Technologies, Rockville, MD, USA) with $100 \mathrm{~mL} / \mathrm{L}$ fetal bovine serum (HyClone Laboratories, Logan, UT, USA) and maintained in a $5 \% \mathrm{CO}_{2}$ incubator at $37^{\circ} \mathrm{C}$. The medium for LNCaP culture was supplemented with $1 \mathrm{nM}$ synthetic hormone methyltrienolone (R1881) (New England Nuclear, Boston, MA, USA). The cells were grown until near confluency, detached, washed with PBS, and counted. Unlike the SP2/0 cells, the LNCaP cells were detached by trypsin-EDTA treatment. The SP2/0 samples of $2.5 \times 10^{6}$ cells and the dilutions of LNCaP cells were stored at $-70^{\circ} \mathrm{C}$ until RNA extraction.

\section{Synthesis and Labeling of Oligonucleotides}

The synthesis of PCR primers, detection probes, and DNA targets, along with the biotinylation of the $3^{\prime}$ PCR primer and the DNA targets, was carried out as reported previously (Table 1) (44). The detection probes for the hybridization assay contained additional diaminohexanedeoxycytidines $(\bmod C)$ to be labeled with lanthanide chelate as described earlier $(5,12,36)$. The detection probe for PSA was labeled with the $\mathrm{Eu}^{3+}$ chelate, and the probe for the IS was labeled either with the $\mathrm{Eu}^{3+}$ chelate for use in the singlelabel assay or with the $\mathrm{Tb}^{3+}$ chelate for use in the dual-label assay.

Vol. 30, No. 4 (2001)

\section{RNA Extraction}

Total RNA was extracted from the pelleted LNCaP and SP $2 / 0$ cells using a TRIzOL ${ }^{\circledR}$ reagent (Life Technologies). This method is based on the acid guanidinium thiocyanate-phenol-chloroform isolation (4). The RNA extraction was performed according to the manufacturer's instructions. Briefly, LNCaP and SP2/0 cells were denatured with the TRIzOL reagent and combined to have a calculated amount of 1, 5, 10, 50, 100, 500 , and 1000 denatured LNCaP cells in $2.5 \times 10^{6} \mathrm{SP} 2 / 0$ cells. A constant amount of IS mRNA $\left(5 \times 10^{4}\right.$ molecules) was added into each sample after denaturation of the cells. The full-length PSA-like IS mRNA was produced in vitro and purified as described earlier (44). After TRIzOL and 1-Bromo-3-Chloropropane (Sigma, St. Louis, MO, USA) treatment, RNA in the aqueous phase was precipitated once with isopropanol. The RNA pellet was washed twice with cold $700 \mathrm{~mL} / \mathrm{L}$ ethanol, air dried and dissolved in $80 \mu \mathrm{L}$ diethylpyrocarbonate (DEPC)-treated water. The RNA preparations were stored at $-70^{\circ} \mathrm{C}$ until they were analyzed with RT-PCR assay.

\section{RT-PCR Amplification}

The cDNA synthesis was carried out with a First-Strand cDNA Synthesis Kit (Amersham Pharmacia Biotech, Uppsala, Sweden) (44). Each cDNA synthesis contained samples for the calibration curve using in vitro produced and purified PSA and IS mRNA diluted in $0.2 \mathrm{~g} / \mathrm{L} \mathrm{E}$. coli tRNA (Roche Molecular Biochemicals, Mannheim, Germany) solution, which was used as an inert carrier solution. After the synthesis, a $5-\mu \mathrm{L}$ cDNA sample was amplified in a $100-\mu \mathrm{L}$ PCR, which consisted of $10 \mathrm{mM}$ Tris- $\mathrm{HCl}, \mathrm{pH} 8.8,50 \mathrm{mM}$ $\mathrm{KCl}, 0.1 \%$ Triton $^{\circledR} \mathrm{X}-100,3.5 \mathrm{mM}$ $\mathrm{MgCl}_{2}, 200 \mu \mathrm{M}$ each dNTP, $0.2 \mu \mathrm{M} 5^{\prime}$ primer a, $0.035 \mu \mathrm{M}$ biotinylated $3^{\prime}$ primer b, $0.065 \mu \mathrm{M}$ unlabeled $3^{\prime}$ primer c, and $1 \mathrm{U}$ DynaZyme ${ }^{\mathrm{TM}}$ II Recombinant DNA Polymerase (Finnzymes Oy, Espoo, Finland). Before amplification the PCRs were kept on ice. The PCR amplifications were performed in a PTC-200 ${ }^{\mathrm{TM}}$ DNA Engine (MJ Research, Watertown, MA, USA) using a program of $94^{\circ} \mathrm{C}$ for $30 \mathrm{~s}$ 


\section{Research Report}

Table 1. Names, Sequences, Labels, and Degrees of Labeling of Primers and Probes Used in This Study

\begin{tabular}{|c|c|c|c|c|}
\hline Oligonucleotide & Name & Sequence from $5^{\prime}$ to $3^{\prime}$ End & Label & $\begin{array}{l}\text { Labels/ } \\
\text { Oligonucleotide }\end{array}$ \\
\hline \multicolumn{5}{|l|}{ PCR } \\
\hline $5^{\prime}$ primer & a & TGAACCAGAGGAGTTCTTGAC & -a & - \\
\hline $3^{\prime}$ primer & $\mathrm{b}$ & (modC)CCCAGAATCACCCGAGCAG & Biotin & 1 \\
\hline $3^{\prime}$ primer & c & (modC)CCCAGAATCACCCGAGCAG & - & - \\
\hline \multicolumn{5}{|l|}{ Hybridization Assay } \\
\hline PSA probe & $d$ & $(\operatorname{modC})_{20}$ GCGCAAGTTCACCCTCA & $\mathrm{Eu}^{3+}$ & 17 \\
\hline IS probe & e & $(\operatorname{modC})_{20} G T G C G C A A T C A C C C T C$ & $\mathrm{Eu}^{3+}$ & 15 \\
\hline IS probe & $f$ & $(\operatorname{modC})_{20} G T G C G C A A T C A C C C T C$ & $\mathrm{~Tb}^{3+}$ & 22 \\
\hline PSA target DNA & $g$ & (modC)CCTTCTGAGGGTGAACTTGCGCACACA & Biotin & 1 \\
\hline IS target DNA & $\mathrm{h}$ & (modC)CCTTCTGAGGGTGATTGCGCACACACG & Biotin & 1 \\
\hline
\end{tabular}

(3 min for the first cycle), $61.5^{\circ} \mathrm{C}$ for 30 $\mathrm{s}$, and $72^{\circ} \mathrm{C}$ for $45 \mathrm{~s}(10 \mathrm{~min} 45 \mathrm{~s}$ for the last cycle) for 30 cycles.

\section{Hybridization}

The products of the PCR amplification were analyzed either with single- or dual-label assay formats as shown in Figure 2. A $10-\mu \mathrm{L}$ aliquot of PCR product and $50 \mu \mathrm{L}$ DELFIA $^{\circledR}$ Assay Buffer containing $1 \mathrm{M} \mathrm{NaCl}$ were added into each streptavidin-coated microtiter well (PerkinElmer Life Sciences Wallac, Turku, Finland). In the single-label assay, each PCR product was added into four wells, the first two replicas were detected with the $\mathrm{Eu}^{3+}$-labeled PSA hybridization probe and the second two replicas were detected with the $\mathrm{Eu}^{3+}$-labeled IS probe. In the dual-label assay, each PCR product was added into two wells, and the PSA and IS products were detected from the same wells with the $\mathrm{Eu}^{3+}$-labeled PSA and $\mathrm{Tb}^{3+}$-labeled IS probes, respectively. PCR amplification and the biotinylated 3 ' primer (b) resulted in biotinylated PCR products, which were captured onto the wells by incubating at room temperature with slow shaking for $30 \mathrm{~min}$. After the capture reaction, the wells were washed three times with DELFIA Wash Solution, and 100 $\mu \mathrm{L} 50 \mathrm{mM} \mathrm{NaOH}$ were added into each well for the denaturation of the doublestranded PCR products. Denaturation was carried out by incubating at room temperature with slow shaking for 5 min; the denatured DNA strand was then removed by washing three times as described above. The captured DNA strand was detected by adding $100 \mu \mathrm{L}$ hybridization solution containing a detection probe or detection probes in DELFIA Assay Buffer containing 0.1\% non-fat milk powder and $1 \mathrm{M} \mathrm{NaCl}$. The hybridization solutions of the single-label assay contained $20 \mathrm{pg} / \mu \mathrm{L}$ detection probe (Table 1, d or e), and that of the dual-label assay contained $20 \mathrm{pg} / \mu \mathrm{L}$ PSA probe (d) and $10 \mathrm{pg} / \mu \mathrm{L}$ IS probe (f). After hybridization at $50^{\circ} \mathrm{C}$ for $2 \mathrm{~h}$, the wells were washed six times with $55^{\circ} \mathrm{C}$ DELFIA Wash Solution. Then, $200 \mu$ L DELFIA Enhancement Solution were added into each well, and after shaking for $30 \mathrm{~min}$ at room temperature, the $\mathrm{Eu}^{3+}$ fluorescence was measured with 1420 Victor $^{\mathrm{TM}}$ Multilabel Counter (Perkin Elmer Life Sciences Wallac). In the dual-label assay after the measurement of $\mathrm{Eu}^{3+}$ fluorescence, $50 \mu \mathrm{L}$ DELFIA Enhancer was added into each well, and after a 5-min incubation, the $\mathrm{Tb}^{3+}$ fluorescence was measured.

\section{RESULTS}

\section{Assay Design}

The dual-label hybridization assay was developed to detect both PSA and IS amplification products simultane- ously from the same microtiter well. For the dual-label assay, the detection probe for IS (f) was labeled with the $\mathrm{Tb}^{3+}$ chelate instead of with the $\mathrm{Eu}^{3+}$ chelate, which was used for labeling the IS probe in the single-label assay. The $\mathrm{Eu}^{3+}$-labeled PSA probe (d) and the sequences of the PSA and IS detection probes were the same in both the single- and the dual-label assays.

Synthetic DNA targets ( $g$ and $h$ ) were used to optimize the amount of $\mathrm{Tb}^{3+}$-labeled IS hybridization probe and the simultaneous detection of PSA and IS targets in the same microtiter well. In the dual-label assay, the highest efficiency in hybridization was obtained with hybridization solution containing $10 \mathrm{pg} / \mu \mathrm{L}$ $\mathrm{Tb}^{3+}$-labeled IS probe (f) and $20 \mathrm{pg} / \mu \mathrm{L}$ PSA probe (d). The other hybridization conditions for the dual-label assay were the same as those for the single-label assay (see Materials and Methods).

The emission peaks of the $\mathrm{Tb}^{3+}$ and $\mathrm{Eu}^{3+}$ chelates are sharp (Figure 1), and the fluorescence signals can be clearly distinguished by measuring the signals at different wavelengths. However, the relative fluorescence intensity of the $\mathrm{Tb}^{3+}$ chelate is smaller than that of the $\mathrm{Eu}^{3+}$ chelate; therefore, the fluorescence signals (counts per second) obtained with the $\mathrm{Tb}^{3+}$-labeled IS probe are lower than those obtained with the $\mathrm{Eu}^{3+}$-labeled IS probe. Because of the lower relative $\mathrm{Tb}^{3+}$ fluorescence, the amount of IS mRNA was raised from 1 


\section{SAMPLE PREPARATION}

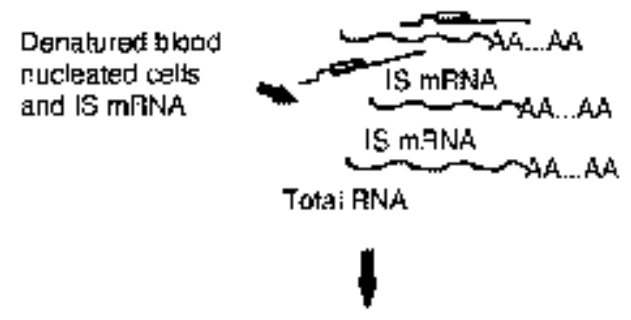

RT-PCR AMPLIFICATION

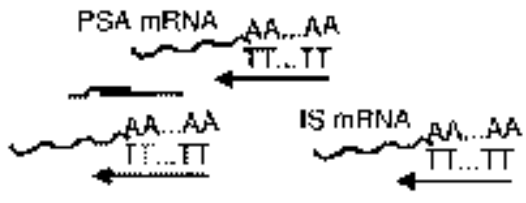

$\checkmark$

PSA and IS specitic primers
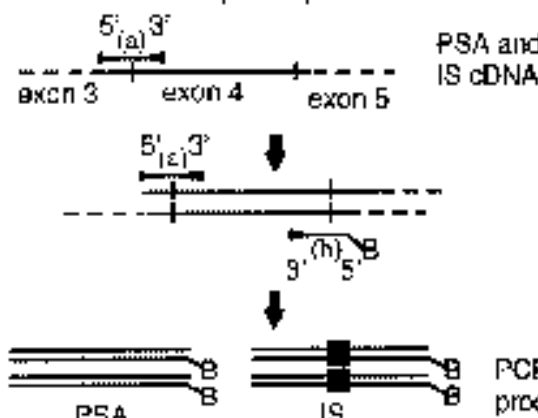

PSA

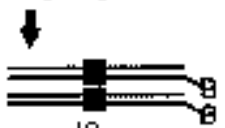

PCA

Is

prowuct

\section{DETECTION OF AMPLIFICATION PAODUCTS}

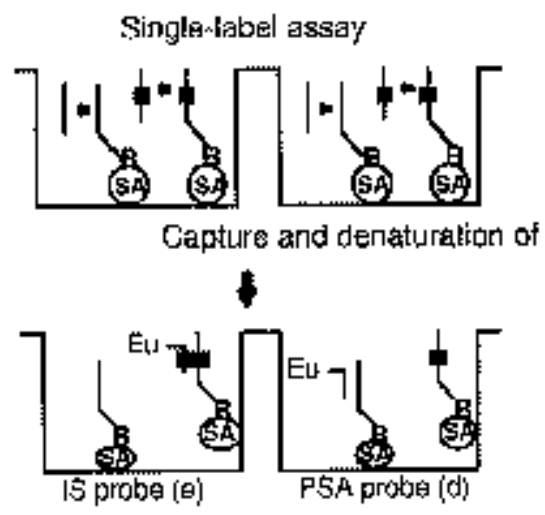

Duat-label assay

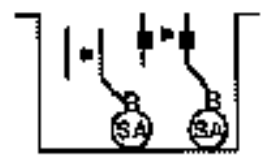

PCR products

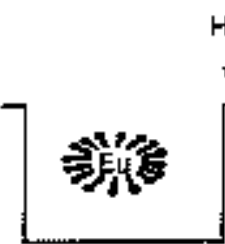

15

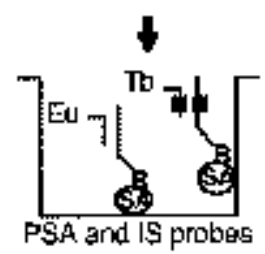

(d and?)

Hybridizafian and slringeril wash

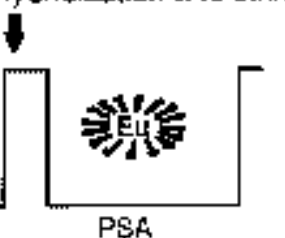

Messurement of fiucresonce $\times 10^{3}$ to $5 \times 10^{3}$ copies for the calibration curve and for the quantification of PSA mRNA in the samples. The use of $5 \times 10^{3}$ IS mRNA copies gave good linearity (from 50 to $10^{6}$ PSA mRNA copies) for the calibration curve, which was similar to the curve generated with the single-label assay and $10^{3}$ IS mRNA copies (Figure 3 ). For the quantification of PSA mRNA in the sam ples, $5 \times 10^{4}$ copies of IS mRNA were added into each sample at the beginning of the RNA extraction, and the RNA pellet was dissolved into $80 \mu \mathrm{L}$ DEPCtreated water. One tenth $(8 \mu \mathrm{L})$ of each sample (corresponding to $5 \times 10^{3}$ copies of IS mRNA in theory) was then analyzed with the QRT-PCR assay.

\section{Precision and Detection Limit of the Assay}

Precision of the optimized dual-label hybridization assay was compared with that of the single-label assay using the QRT-PCR amplified samples for the calibration curve and two replicas of each sample in each of the five independent analyses. The within-assay precision over the calibration range (50-106 PSA mRNA copies, $5 \times 10^{3}$ IS mRNA for the dual-label and $10^{3}$ IS mRNA for the single-label assay in each) was $2.5 \%-21.7 \%$ for the singlelabel assay and $0.8 \%-7.5 \%$ for the dual-label assay (Figure 4A). The between-assay precision over the calibration range was $8.9 \%-36.0 \%$ for the single-label assay and $11.8 \%-30.3 \%$ for the dual-label assay (Figure 4B). With both the single- and the dual-label assays, the smallest detectable number of PSA mRNA was 50 copies, and the lin-

Figure 2. Principle of single- and dual-label assays. A known amount of IS mRNA is added into a mixture of denatured cells, and then PSA and IS mRNAs in the sample are co-extracted in total RNA isolation. PSA and IS mRNAs in the RNA sample or calibrator are co-amplified by RT-PCR (primers a and $b$ ). One of the PCR primers (b) is biotinylated (B), which results in biotinylated amplification products. The amplification products are captured on streptavidin (SA)-coated microtiter wells. In the single-label hybridization assay, the PSA and IS PCR products are detected separately with specific europium chelate-labeled detection probes (d and e) (44). In the dual-label assay, PSA and IS PCR products are detected with europium and terbium chelate-labeled probes (d and f), respectively. 


\section{Research Report}

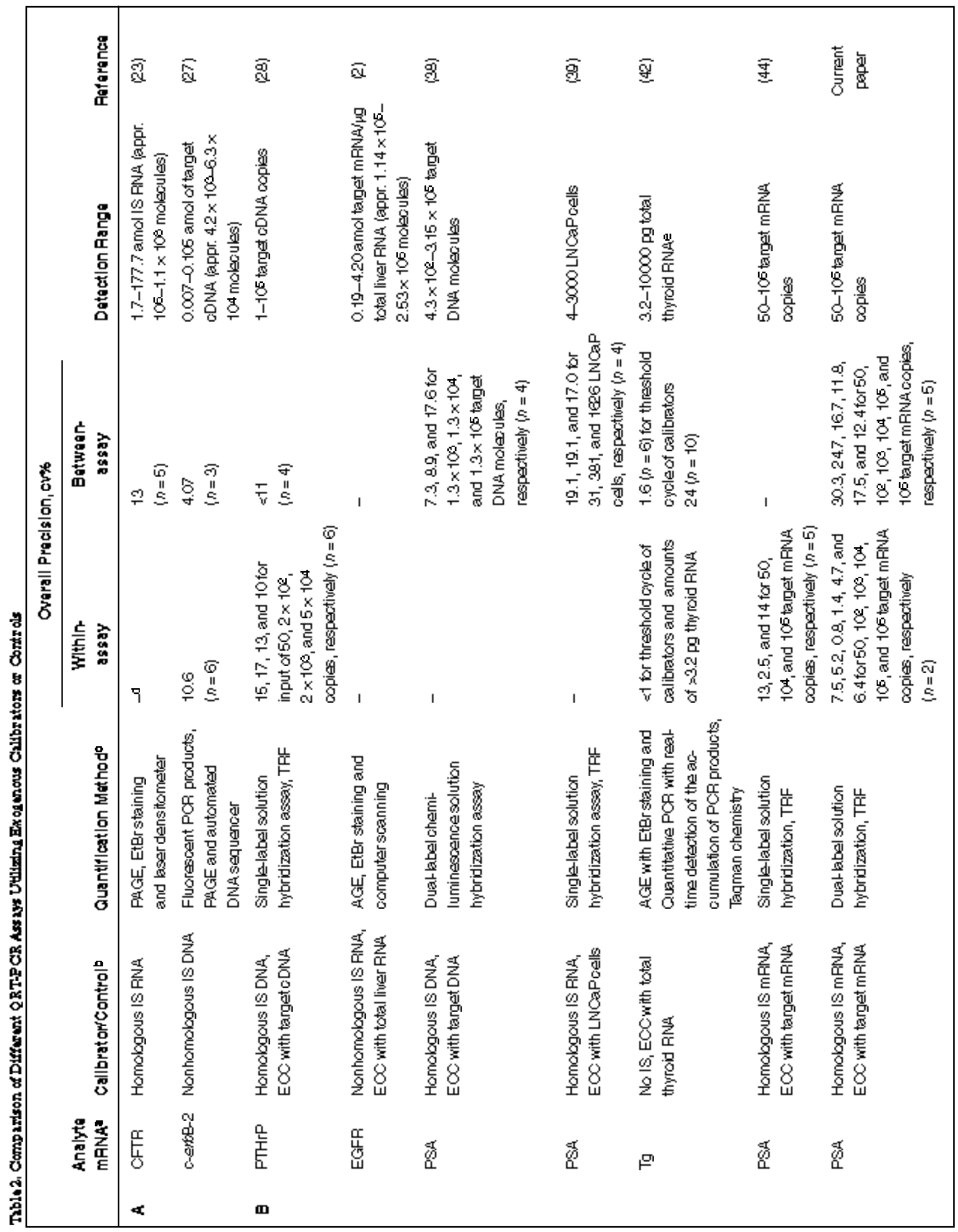




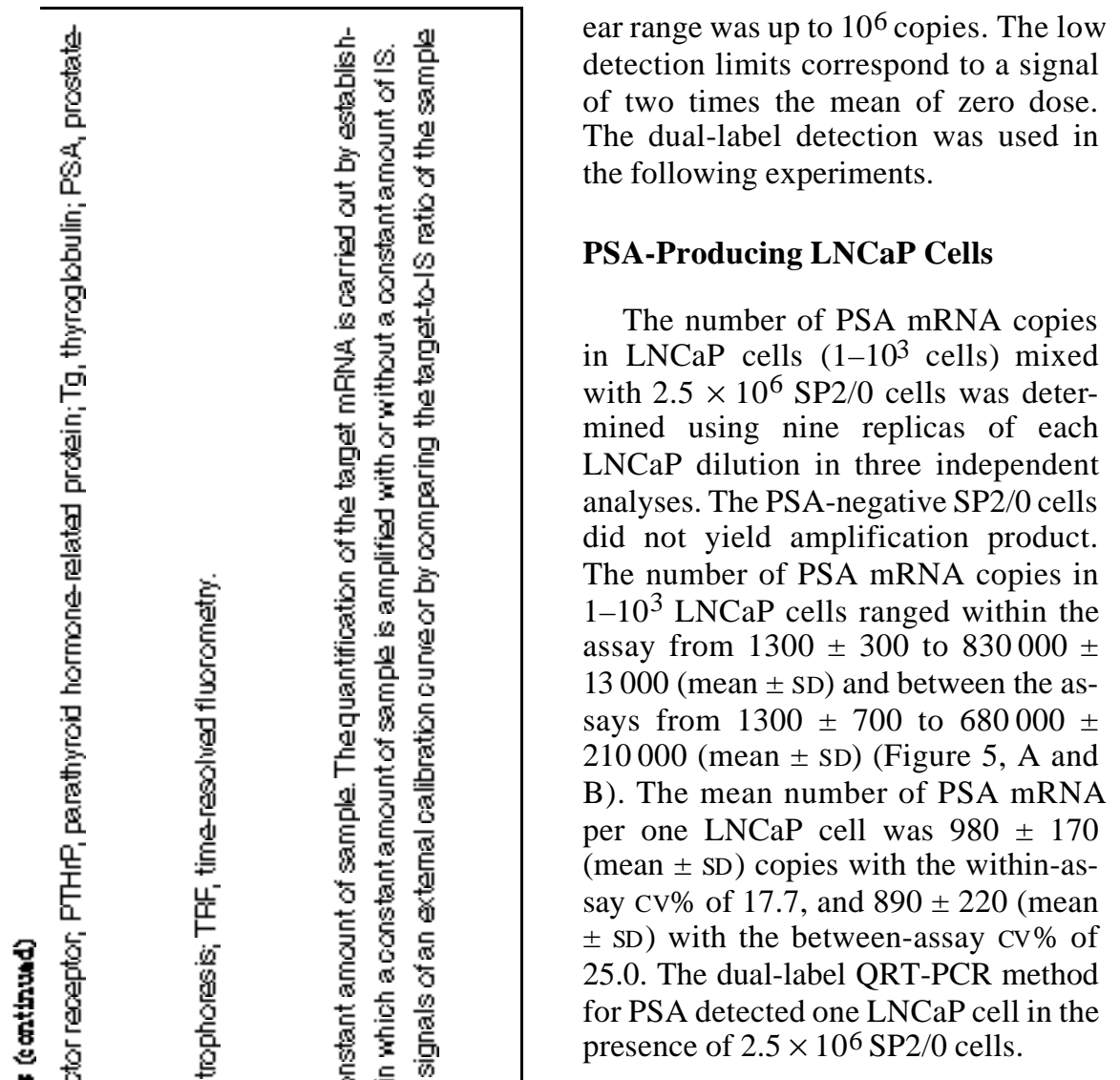

\section{DISCUSSION}

QRT-PCR assays have been developed to contain either endogenous or exogenous controls or calibrators, which can be either external or internal. Originally, Chelly et al. (3) used an endogenous internal calibrator for the relative quantification of the target mRNA. In this method, the calibrator and target were amplified with different primers. Furthermore, some of the studies used an exogenous target-like IS RNA or DNA using dilutions of the IS for the quantification of the target mRNA $(1,23,27,41)$. More recently, the quantification of the target mRNA has been carried out using a constant amount of IS in each sample and an external calibration curve consisting of the dilutions of calibrator and a constant amount of IS in each $(2,28,38,39,42,44)$.

Table 2 summarizes some studies $(2,23,27,28,38,39,42,44)$ that report the precision or the detection range of their QRT-PCR assays and that utilize an exogenous IS (panel A) and/or an external calibration curve (panel B). There are many RT-PCR assays each utilizing its own principle, which makes the direct comparison of different assays quite difficult. However, there are some facts that need to be taken into account when developing a QRT-PCR assay with an exogenous IS and/or an external calibration curve. For the quantification of the target, it is a prerequisite that the target and the IS are amplified with the same efficiency. The assays in Table 2 employ different types of IS, which are either DNA or RNA, and either homologous or non-homologous with respect to the target. The same amplification efficiency can be achieved by developing an IS with similar sequence and size with respect to the target so that they can be co-amplified with the same primers and result in amplification products of similar size. Furthermore, to obtain selective detection of the amplification products, the IS should contain a small but distinguishable difference in its amplified sequence with respect to the target, and there should be a sophisticated detection method to quantify the target and the IS PCR products.

The IS DNA and IS RNA control different steps, to some extent, during the quantification of target mRNA by RT-PCR. The use of IS DNA makes it possible to quantify the target cDNA and controls variations from the PCR step to the detection of amplification

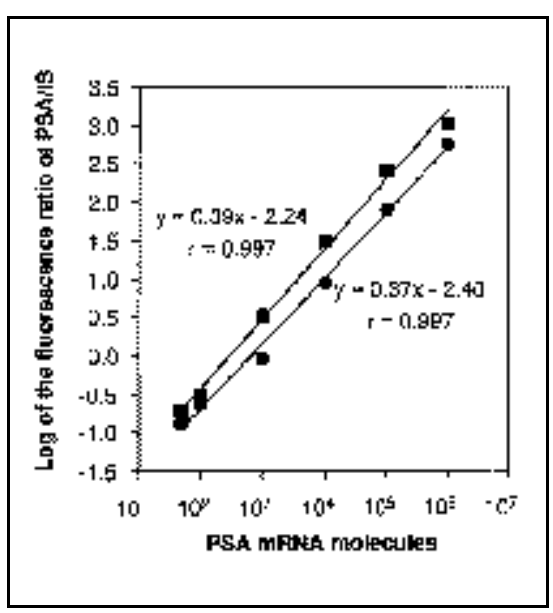

Figure 3. Comparison of calibration curves generated with single- and dual-label assays. Squares indicate the curve for the single-label assay containing 50-106 initial PSA mRNA molecules with $10^{3}$ IS mRNA in each. Circles indicate the curve for the dual-label assay containing 50-106 initial PSA mRNA molecules with $5 \times$ $10^{3}$ IS mRNA in each. 
products $(27,28,38)$. IS RNA enables quantification of the target from RNA level and controls the variations from the beginning of RT-PCR to the detection of amplification products $(2,23$, 39). However, the RNA extraction step should be also controlled. In our current and previous work (44), the target-like IS mRNA is added into the cell samples at the beginning of the RNA extraction, and the assays are controlled from the RNA extraction to the hybridization assay used for the detection of the am plification products. Therefore, the amount of target mRNA represents the number of mRNA copies in the denatured cell pellet before the RNA extraction. However, no assays exist that control the collection of the target cells from the biological material, which cannot provide information whether there are a few cells that contain many target mRNA copies or many cells that contain a few target mRNA copies.

There are two main principles in the use of an exogenous IS for the quantification of the target mRNA. The first principle is to amplify serial dilutions of IS (or sample) with a constant amount of sample (or IS) and quantify the target mRNA by establishing an equivalency point between the IS and the target $(23,27)$. This method requires many tubes for the analysis of one sample and therefore limits the number of samples that can be analyzed in one experiment. The second principle is to amplify a constant amount of IS in each sample and in each of the calibrators covering a certain concentration range of the target $(2,28,38,39,44)$. The concentration of the target mRNA in the sample can then be calculated from the

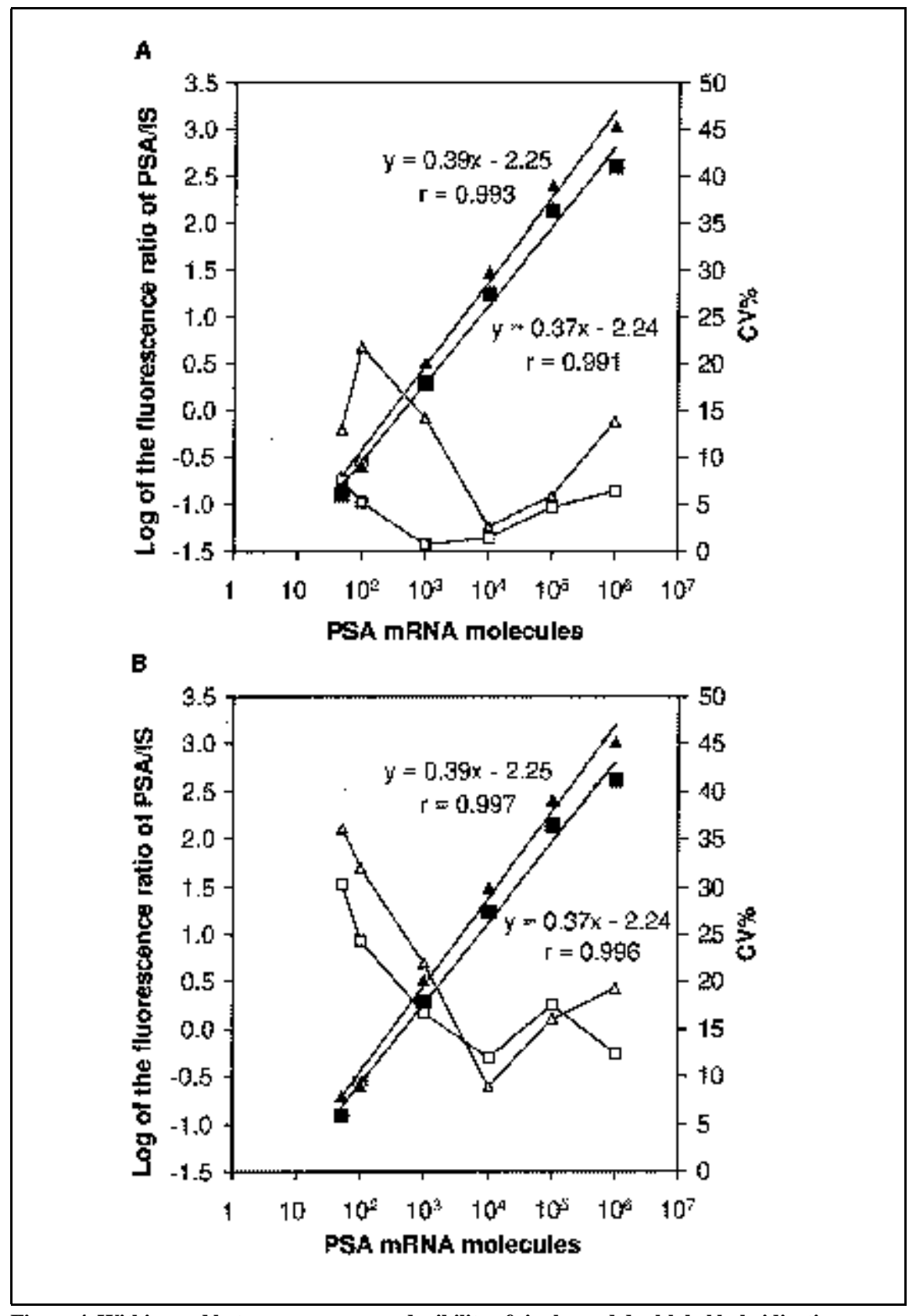

Figure 4. Within- and between-assay reproducibility of single- and dual-label hybridization assays over the calibration range (50-106 PSA mRNA copies, $5 \times 10^{3}$ IS mRNA for the dual-label, and $10^{3}$ IS mRNA for the single-label assay in each). Panel A represents the within-assay reproducibility, and panel B represents the between-assay reproducibility. Closed and open triangles indicate the calibration curve and its $\mathrm{CV}$ values for the single-label assay, respectively. Closed and open squares indicate the calibration curve and its $\mathrm{CV}$ values for the dual-label assay. 
calibration curve by comparing the target-to-IS ratio in the sample to the target-to-IS ratio in the calibration curve. The analysis of one sample needs only one tube, and the number of target copies can be calculated using the external calibration curve. However, in addition to the development of the IS, this method needs preparation of the calibrator material. At the same time, this method allows the analysis of multiple samples in the same experiment.

We described here a TRF-based dual-label hybridization assay combined with the QRT-PCR assay for the quantification of PSA mRNA. Our QRTPCR assay was based on the use of an exogenous IS mRNA and an external calibration curve generated with PSA mRNA and IS mRNA (covering the range of 50-106 PSA mRNA copies). The quantification of PSA mRNA copies in the sample was carried out by calculating the fluorescence ratio of PSA-to-IS in the sample and by comparing the ratio to that in the calibration curve. Each assay contained the external calibration curve and one tube for the analysis of one sample. The PSA-like IS mRNA contained only a 2-bp difference with respect to the PSA mRNA. The IS mRNA was added to the sample at the beginning of RNA extraction; thus, the IS controlled the variations from the RNA extraction to the hybridization assay and could be used for the quantification of PSA mRNA copies in the sam ple. We have shown earlier that PSA mRNA and IS mRNA are amplified with the same efficiency and that the two amplification products are selectively detected by the hybridization assay (44). The present dual-label hybridization assay was developed to detect the amplified PSA and IS products simultaneously from a single microtiter well and to improve the reproducibility of the PSA mRNA quantification. The hybridization assay utilized PSA- and IS-specific detection probes labeled with different lanthanide chelates, which had different emission wavelengths and sharp emission peaks, allowing separation of the signals and the simultaneous detection of the PSA and IS amplification products. The analyses of a large number of samples using dual-label TRF and microplatebased method was easier to perform, more rapid, and more sensitive than using the conventional analyses based on gel electrophoresis, Southern blot, and membrane hybridization. The numerical results produced by the TRF method were useful for the exact quantification of PSA mRNA. The QRT-PCR assay with the dual-label detection improved the within-assay precision over the calibration range (50-106 PSA mRNA copies, $5 \times 10^{3}$ IS mRNA for the duallabel and $10^{3}$ IS mRNA for the singlelabel assay in each) from $21.7 \%$ to $7.5 \%$ when compared to the single-label assay. Correspondingly, the between-assay precision was slightly improved from $36.0 \%$ to $30.3 \%$ using the dual-label assay. The dual-label detection of the amplification products was more reproducible and obviously a lot simpler to carry out than the single-label assay; therefore, the dual-label assay was evaluated in the following experiments. The within- and between-assay CVs for the dual-label assay including all the steps from the RNA extraction to the hybridization were studied using LNCaP cells. One LNCaP cell was found to express $980 \pm 170$ (mean \pm SD) copies of PSA mRNA with the within-assay CV \% of 17.7 , and $890 \pm 220$ (mean \pm SD) copies of PSA mRNA with the betweenassay CV\% of 25.0. The single- and dual-label assays had the same detection limit, linear assay range and ability to detect one $\mathrm{LNCaP}$ cell in $2.5 \times 10^{6}$ nonPSA-producing cells. The number of PSA mRNA copies in LNCaP cells is in accordance with our previous results when PSA mRNA copies were determined in four replicas within one run. However, the present study reports more extensive determination of PSA mRNA in LNCaP cells. To our knowledge, we are the first to report the exact number of PSA mRNA copies in LNCaP cells. Additionally, the developed assay offers a suitable tool for further studies to study cell lines expressing PSA mRNA.

Lately, novel label technologies have contributed to the development of new methods that are applicable for the detection of accumulating PCR product directly from a closed tube $(11,22$, $24,25,37)$. The use of such a real-time detection of PCR product from a closed tube decreases the risk of carry-over contamination because the amplification and the detection steps take place in 
the same tube. Therefore, there is no need to open the tubes after PCR. In addition, this approach simplifies the assays by eliminating the post-PCR analysis and allows the analysis of a large number of samples simultaneously. These methods can be used in both quantitative PCR and QRT-PCR assays $(9,10,42)$. A commonly used approach for the quantification of the target is to amplify several samples and an external calibration curve generated with targetlike DNA or RNA in the same run (42). The real-time detection of amplification products is performed at the exponential phase of PCR when the accumulating PCR product gives a signal above the threshold cycle. This method gives very reproducible results, as shown by

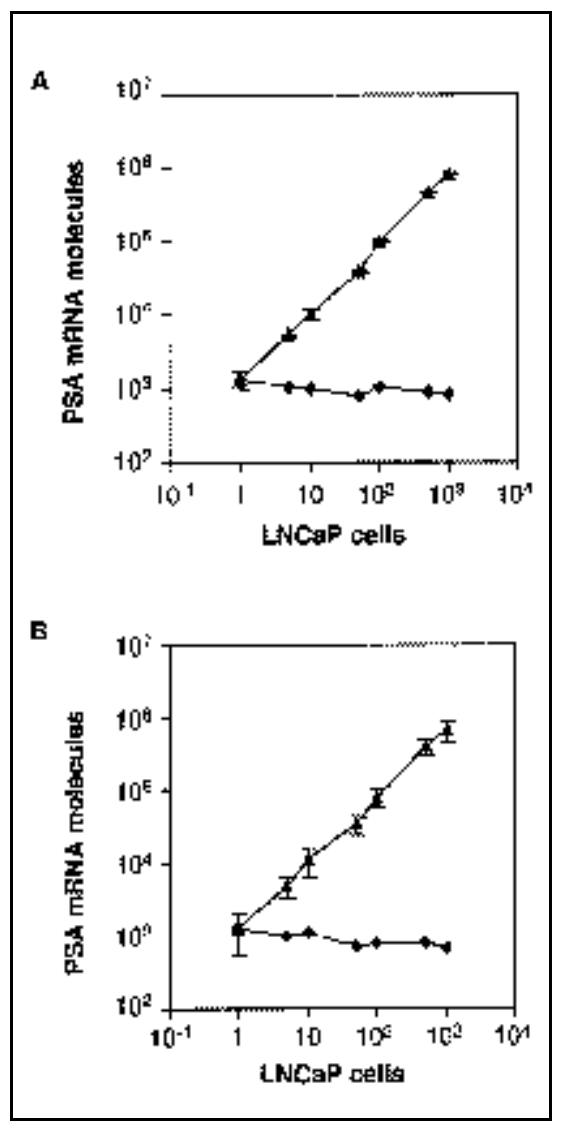

Figure 5. Within- and between-assay reproducibility of number of PSA mRNA copies in LNCaP cells. Panel A represents the within-assay reproducibility of the mean number of PSA mRNA copies (closed triangles), and the error bars show the SD of nine replicas. Panel B represents the between-assay reproducibility of the mean of PSA mRNA copies (closed triangles), and the error bars show the SD of three independent analyses. Closed diamonds in both panels indicate the mean number of PSA mRNA copies per LNCaP cell.
Wingo et al. (Table 2) (42). However, in RT-PCR assays, it is also important to control the pre-PCR steps, which are usually carried out by amplifying the target transcript and an endogenous housekeeping gene transcript in the same PCR. The number of target mRNA copies can then be normalized with the mRNA expression of the housekeeping gene. This kind of relative quantification is possible to carry out because the signals are measured at the exponential phase of PCR while the amplification efficiencies are at their highest and adjustable by optimization to be the same for both the target and the housekeeping gene transcript. Nevertheless, even after careful optimization of the PCR step, it can be difficult to use abundantly expressed housekeeping mRNA for the quantification and normalization of the number of infrequently expressed target mRNA. This problem was overcome when target-like IS mRNA was used in addition to an external calibration curve. The new technologies allow the real-time detection of PCR products from a closed tube, which will be the method of choice for quantitative PCR and RT-PCR analysis in routine use and diagnostic purposes.

In conclusion, the assay described here possesses a wide linear detection range of five orders of magnitude, which is similar to the detection range of the assays reported by Rong et al. (28) and Verhaegen et al. $(38,39)$ (Table 2). Furthermore, the simultaneous detection of PSA and IS amplification products from one microtiter well gives reasonably good within- and betweenassay reproducibility comparable to other end-point RT-PCR assays. In our assay, the PSA-like IS mRNA allows variations to be controlled from the beginning of RNA extraction to the detection of amplification products, which is different from other assays utilizing IS RNA or IS DNA for the control of variations from RT-PCR or from PCR steps to the detection of amplification products. The present dual analyte assay has been shown to be applicable for accurate detection of PSA mRNA copies in LNCaP cell samples and, therefore, can be used in further studies to quantify PSA mRNA in cultured PSA-producing cells or in circulating prostate cancer cells. More broadly, a similar approach should prove useful for monitoring other types of metastasizing cancer cells such as those associated with breast cancer.

\section{ACKNOWLEDGMENTS}

This work was supported by grants from the Biomed 2 Program, area 4.1.7. (Contract BMH4-CT96-0453), the Swedish Cancer Society (project no. 3555), the Faculty of Medicine at Lund Unversity Hospital, Malmö, the Crafoord Foundation, the Gunnar, Arvid and Elisabeth Nilsson Foundation, and Fundacion Frederico S.A. We thank Sari Lindgren and Pauliina Nurmikko for providing the LNCaP and SP2/0 cells, Minna Kujanpää for the synthesized, labeled, and purified oligonucleotides, and Minna-Liisa Änkö for technical assistance in the development of the duallabel hybridization assay.

\section{REFERENCES}

1.Becker-André, M. and K. Hahlbrock. 1989. Absolute mRNA quantification using the polymerase chain reaction (PCR). A novel approach by a PCR aided transcript titration assay (PATTY). Nucleic Acids Res. 17: 9437-9446

2.Bor, M.V., B.S. Sørensen, P. Rammer, and E. Nexø. 1998. Calibrated user-friendly reverse transcriptase-PCR assay: quantitation of epidermal growth factor receptor mRNA. Clin. Chem. 44:1154-1160.

3.Chelly, J., J.C. Kaplan, P. Maire, S. Gautron, and A. Kahn. 1988. Transcription of the dystrophin gene in human muscle and non-muscle tissue. Nature 333:858-860.

4.Chomczynski, P. and N. Sacchi. 1987. Single-step method of RNA isolation by acid guanidinium thiocyanate-phenol-chloroform extraction. Anal. Biochem. 162:156-159.

5.Dahlén, P.O., A.J. Iitiä, G. Skagius, A. Frostell, M.F. Nunn, and M. Kwiatkowski. 1991. Detection of human immunodeficiency virus type 1 by using the polymerase chain reaction and a time-resolved fluorescence-based hybridization assay. J. Clin. Microbiol. 29:798-804.

6.De La Taille, A., C.A. Olsson, R. Buttyan, M.C. Benson, E. Bagiella, Y. Cao, M. Burchardt, D.K. Chopin, and A.E. Katz. 1999. Blood-based reverse transcriptase polymerase chain reaction assays for prostatic specific antigen: long term follow-up confirms the potential utility of this assay in identifying patients more likely to have biochemical recurrence (rising PSA) following radical prostatectomy. Int. J. Cancer. 84:360-364.

7.Gala, J.L., M. Heusterspreute, S. Loric, F. Hanon, B. Tombal, P. Van Cangh, P. De Nayer, and M. Philippe. 1998. Expression of 
prostate-specific antigen and prostate-specific membrane antigen transcripts in blood cells: implications for the detection of hematogenous prostate cells and standardization. Clin. Chem. 44:472-481.

8.Galvan, B., T.K. Christopoulos, and E.P. Diamandis. 1995. Detection of prostate-specific antigen mRNA by reverse transcription polymerase chain reaction and time-resolved fluorometry. Clin. Chem. 41:1705-1709.

9.Gibson, U.E., C.A. Heid, and P.M. Williams. 1996. A novel method for real time quantitative RT-PCR. Genome Res. 6:995-1001.

10.Heid, C.A., J. Stevens, K.J. Livak, and P.M. Williams. 1996. Real time quantitative PCR. Genome Res. 6:986-994.

11.Holland, P.M., R.D. Abramson, R. Watson, and D.H. Gelfand. 1991. Detection of specific polymerase chain reaction product by utilizing the $5^{\prime} \rightarrow 3^{\prime}$ exonuclease activity of Thermus aquaticus DNA polymerase. Proc. Natl. Acad. Sci. USA. 88:7276-7280.

12.Hurskainen, P., P. Dahlén, J. Ylikoski, M. Kwiatkowski, H. Siitari, and T. Lövgren. 1991. Preparation of europium-labelled DNA probes and their properties. Nucleic Acids Res. 19:1057-1061.

13.Iitiä, A., L. Liukkonen, and H. Siitari. 1992. Simultaneous detection of two cystic fibrosis alleles using dual-label time-resolved fluorom etry. Mol. Cell Probes 6:505-512.

14.Iitiä, A., M. Mikola, N. Gregersen, P. Hurskainen, and T. Lövgren. 1994. Detection of a point mutation using short oligonucleotide probes in allele-specific hybridization. BioTechniques. 17:566-573

15.Israeli, R.S., W.H. Miller, Jr., S.L. Su, C.T. Powell, W.R. Fair, D.S. Samadi, R.F. Huryk, A. DeBlasio et al. 1994. Sensitive nested reverse transcription polymerase chain reaction detection of circulating prostatic tumor cells: comparison of prostate-specific membrane antigen and prostate-specific antigen-based assays. Cancer Res. 54:6306-6310.

16.Katz, A.E., C.A. Olsson, A.J. Raffo, C. Cama, H. Perlman, E. Seaman, K.M. O'Toole, D. McMahon, M.C. Benson, and R. Buttyan. 1994. Molecular staging of prostate cancer with the use of an enhanced reverse transcriptase-PCR assay. Urology 43:765-775.

17.Komeda, T., Y. Fukuda, T. Sando, R. Kita, M. Furukawa, N. Nishida, M. Amenomori, and K. Nakao. 1995. Sensitive detection of circulating hepatocellular carcinoma cells in peripheral venous blood. Cancer 75:22142219.

18.Lövgren, T. and K. Pettersson. 1990. Timeresolved fluoroimmunoassay, advantages and limitations., p. 233-253. In K. Van Dyke and R. Van Dyke (Eds.), Luminescence Im munoassay and Molecular Applications. CRC Press, Boca Raton, FL

19.Mattano, J., L.A., T.J. Moss, and S.G. Emerson. 1992. Sensitive detection of rare circulating neuroblastoma cells by the reverse transcriptase-polymerase chain reaction. Cancer Res. 52:4701-4705.

20.Mitrunen, K., K. Pettersson, T. Piironen, T. Björk, H. Lilja, and T. Lövgren. 1995. Duallabel one-step immunoassay for simultaneous measurement of free and total prostate-specific antigen concentrations and ratios in serum.
Clin. Chem. 41:1115-1120.

21.Moreno, J.G., C.M. Croce, R. Fischer, M. Monne, P. Vihko, S.G. Mulholland, and L.G. Gomella. 1992. Detection of hematogenous micrometastasis in patients with prostate cancer. Cancer Res. 52:6110-6112.

22.Morrison, L.E. 1995. Detection of energy transfer and fluorescence quenching, p. 429471. In L.J. Kricka (Ed.), Nonisotopic Probing, Blotting, and Sequencing. Academic Press, San Diego.

23.Mularoni, A., G.L. Adessi, F. Arbez-Gindre, G. Agnani, and M. Nicollier. 1996. Competitive RT-PCR to quantify CFTR mRNA in human endometrium. Clin. Chem. 42:1765-1769.

24.Nazarenko, I.A., S.K. Bhatnagar, and R.J. Hohman. 1997. A closed tube format for am plification and detection of DNA based on energy transfer. Nucleic Acids Res. 25:25162521.

25.Nurmi, J., A. Ylikoski, T. Soukka, M. Karp, and T. Lövgren. 2000. A new label technology for the detection of specific polymerase chain reaction products in a closed tube. $\mathrm{Nu}$ cleic Acids Res. 28:E28.

26.O'Hara, S.M., S.M. Veltri, and P. Skirpstunas. 1996. Basal PSA mRNA levels detected by quantitative reverse transcriptase polymerase chain reaction (Q-RT-PCR-PSA) in blood from subjects without prostate cancer. J. Urol. 155:418A.

27.Révillion, F., L. Hornez, and J.P. Peyrat. 1997. Quantification of c-erbB-2 gene expression in breast cancer by competitive RT-PCR. Clin. Chem. 43:2114-2120.

28.Rong, H., H. Ji, Y. Pernow, U. Sjöstedt, and E. Bucht. 1997. Quantification of parathyroid hormone-related protein mRNA by competitive PCR and time-resolved lanthanide fluorometry. Clin. Chem. 43:2268-2273.

29.Saarma, M., L. Järvekülg, I. Hemmilä, H. Siitari, and R. Sinijärv. 1989. Simultaneous quantification of two plant viruses by doublelabel time-resolved immunofluorometric assay. J. Virol. Methods 23:47-54.

30.Samiotaki, M., M. Kwiatkowski, N. Ylitalo, and U. Landegren. 1997. Seven-color timeresolved fluorescence hybridization analysis of human papilloma virus types. Anal. Biochem. 253:156-161.

31.Sjöroos, M., A. Iitiä, J. Ilonen, H. Reijonen, and T. Lövgren. 1995. Triple-label hybridization assay for type-1 diabetes-related HLA alleles. BioTechniques. 18:870-877.

32.Smith, B., P. Selby, J. Southgate, K. Pittman, C. Bradley, and G.E. Blair. 1991 Detection of melanoma cells in peripheral blood by means of reverse transcriptase and polymerase chain reaction. Lancet 338:12271229.

33.Smith, M.R., S. Biggar, and M. Hussain. 1995. Prostate-specific antigen messenger RNA is expressed in non-prostate cells: implications for detection of micrometastases. Cancer Res. 55:2640-2644.

34.Soini, E. and T. Lövgren. 1987. Time-resolved fluorescence of lanthanide probes and applications in biotechnology. CRC Crit. Rev. Anal. Chem. 18:105-154.

35.Sokoloff, M.H., C.L. Tso, R. Kaboo, S. Nelson, J. Ko, F. Dorey, R.A. Figlin, S. Pang, J. Dekernion, and A. Belldegrun. 1996. Quan- titative polymerase chain reaction does not im prove preoperative prostate cancer staging: a clinicopathological molecular analysis of 121 patients. J. Urol. 156:1560-1566.

36.Sund, C., J. Ylikoski, P. Hurskainen, and M. Kwiatkoeski. 1988. Construction of europium $\left(\mathrm{Eu}^{3}\right)$-labelled oligo DNA hybridization probes. Nucleosides Nucleotides 7:655-659.

37. Tyagi, S. and F.R. Kramer. 1996. Molecular beacons: probes that fluoresce upon hybridization. Nat. Biotechnol. 14:303-308.

38. Verhaegen, M. and T.K. Christopoulos. 1998. Quantitative polymerase chain reaction based on a dual-analyte chemiluminescence hybridization assay for target DNA and internal standard. Anal. Chem. 70:4120-4125.

39. Verhaegen, M., P.C. Ioannou, and T.K. Christopoulos. 1998. Quantification of prostate-specific antigen mRNA by coamplification with a recombinant RNA internal standard and microtiter well-based hybridization. Clin. Chem. 44:1170-1176.

40. Vessella, R.L., D.E. Riley, K.A. Blouke, E.W. Arfman, and P.H. Lange. 1992. A sensitive method for a detection of a prostate tumor cell marker using the polymerase chain reaction. J. Urol. 147:441A.

41.Wang, A.M., M.V. Doyle, and D.F. Mark. 1989. Quantitation of mRNA by the polymerase chain reaction. Proc. Natl. Acad. Sci. USA 86:9717-9721.

42.Wingo, S.T., M.D. Ringel, J.S. Anderson, A.D. Patel, Y.D. Lukes, Y.Y. Djuh, B. Solomon, D. Nicholson et al. 1999. Quantitative reverse transcription-PCR measurement of thyroglobulin mRNA in peripheral blood of healthy subjects. Clin. Chem. 45:785-789.

43. Ylikoski, A., J. Hellman, T. Matikainen, S. M. Käkönen, M. Karp, H.K. Väänänen, T. Lövgren, and K. Pettersson. 1998. A dual-label immunofluorometric assay for human osteocalcin. J. Bone Miner. Res. 13:1183-1190.

44. Ylikoski, A., M. Sjöroos, A. Lundwall, M Karp, T. Lövgren, H. Lilja, and A. Iitiä. 1999. Quantitative reverse transcription-PCR assay with an internal standard for the detection of prostate-specific antigen mRNA. Clin. Chem. 45:1397-1407.

Received 28 June 2000; accepted 30 October 2000

Address correspondence to:

Dr. Alice Ylikoski

Department of Biotechnology

University of Turku

Tykistökatu 6 A 6th floor

FIN-20520 Turku, Finland

e-mail:alice.ylikoski@utu.fi 